\title{
A GEOMORFOLOGIA E A DATAÇÃO DAS GRAVURAS DE FOZ CÔA - METODOLOGIA E DESENVOLVIMENTO DE UM CASO DE INVESTIGAÇÃO CIENTÍFICA
}

\author{
FERNANDO REBELO ${ }^{1}$ e A. M. ROCHETTE CORDEIRO ${ }^{2}$ \\ À Professora Doutora Suzanne Daveau \\ como reconhecimento pelo muito que nos \\ ensinou no âmbito da Geomorfologia
}

\begin{abstract}
Resumo - Começa-se pela apresentação da primeira hipótese posta pelos Autores quanto à idade das gravuras rupestres de Foz Côa, que se baseava nas características climáticas e paleoclimáticas conhecidas para a área, bem como nas características hidrológicas do rio Côa, particularmente no respeitante às cheias, e se apoiava na dedução da origem tardiglaciar das superfícies lisas onde elas se encontram. Em seguida, desenvolvem-se hipóteses alternativas baseadas na dureza de alguns xistos e na subverticalidade de algumas superfícies de fracturação onde se encontram gravuras, e muito especialmente a hipótese de regularização das vertentes por depósitos periglaciares que assim fossilizariam gravuras anteriores. $\mathrm{O}$ facto de se terem encontrado algumas provas inequívocas tanto da acção do gelo em superfícies com gravuras, como da cobertura de outras por depósitos já conhecidos e datados noutras áreas do País levou os Autores a concluirem pela idade paleolítica de algumas das gravuras existentes na área de Foz Côa.
\end{abstract}

Palavras-chave: Foz Côa, datação, gravuras.

\begin{abstract}
THE GEOMORPHOLOGY AND THE DATING OF THE ENGRAVINGS OF Foz CÔA METHODOLOGY AND DEVELOPMENT OF A SCIENTIFIC RESEARCH CASE - Several alternative interpretations of the age of the engravings at Foz Côa are presented. One derivation is based on the climatic and paleo-climatic characteristics of the area as well as the hydrological characteristics of the Côa River, especially its propensity for flooding. This interpretation involves the assumption that the smooth rock surface on which the engravings are found is of late-glacial origin. Another approach at establishing an age is based on the hardness of the rock schists and the near vertical slopes of the smooth surfaces in which the engravings are etched. And another interpretation is related to the burial of the engravings by debris flow and the effects of frost action on the rock surfaces. Evidence of the effects of ice on the rock surface along with the presence of periglacial deposits, similar
\end{abstract}

1 Professor Catedrático da Faculdade de Letras da Universidade de Coimbra. Instituto de Geografia. Largo da Porta Férrea - 3000 Coimbra.

2 Assistente da Faculdade de Letras da Universidade de Coimbra. 
to other known and previously-dated engravings, leads to the identification of a paleolithic age for the engravings found in the Foz Côa area.

Key-words: Foz Côa, dating, engravings.

1. Em termos geomorfológicos, era muito difícil defender a antiguidade das gravuras ditas paleolíticas de Foz Côa tal como, nos inícios de 1995, com base, quase que exclusivamente, em critérios estilísticos, era afirmada por alguns arqueólogos aos órgãos de comunicação social - uma idade de aproximadamente 23000 anos.

É certo que, à partida, o clima da secção terminal do vale do Côa apresenta características vincadamente mediterrâneas, com verões quentes e secos e chuvas (pouco abundantes) de outono, inverno e primavera. Já em 1932, Hermann Lautensach o apresentava na variedade Csa da classificação de Köppen (RIBEIRO, LAUTENSACH e DAVEAU, 1987, p. 367) e, certamente pelas temperaturas elevadas que o caracterizam no verão, no seu «Esboço provisório das regiões climáticas de Portugal», datado de 15/8/79 (DAVEAU e colaboradores, 1980, fig. 9; idem, 1985, fig. 1), Suzanne Daveau integrou-o num «tipo continental, acentuado pela posição topográfica». Ao colocarem essa área do país abaixo dos $500 \mathrm{~mm}$ de precipitação anual média, DAVEAU e colab. (1977) já tinham mesmo feito a sua aproximação ao tipo BSs de Köppen. Aliás, no belíssimo e útil mapa da precipitação anual que então publicaram, este foi o único local de todo o território em que chegaram a representar duas estreitas manchas com menos de $300 \mathrm{~mm}$ de precipitação anual média. Em suma, graças à pouca importância das precipitações, este clima poderia considerar-se um factor favorável à manutenção das gravuras durante alguns milhares de anos.

A verdade, porém, é que, mesmo sob este clima actual, são bem conhecidas as chuvadas fortes (chuvas intensas) que se registam na região. Ao acontecerem na primavera (ou no outono), quando as temperaturas já são (ou ainda são) um pouco elevadas, ou (embora raramente) no verão, quando as temperaturas são muito elevadas, estas chuvas revelam-se agressivas não só do ponto de vista da erosão mecânica, observável nas regueiras que logo se formam nos caminhos, mas também, do ponto de vista físico-químico, não observável a curto prazo, mas facilmente dedutível.

De qualquer modo, sabe-se que este clima não se mantém inalterado desde há milhares de anos... Bem pelo contrário. Ali perto, a menos de $100 \mathrm{~km}$ de distância, na Serra da Estrela, estão provas de que a glaciação do Würm foi importante (DAVEAU, 1971). Mesmo em tempos históricos, ele não foi sempre igual ao de hoje - conhecem-se alguns pequenos períodos frios, por vezes com a duração de duas a três centenas de anos, em que a queda de neve e a sua manutenção no solo, bem como a formação de gelo eram mais frequentes do que nos invernos actuais. E isso não aconteceu só na Europa além Pirinéus (CHALINE, 1985, p. 255-258); para falar apenas de escritos recentes sobre áreas ainda relativamente próximas, também para 
a Serra do Marão (PEDROSA, 1994, p. 25) e para a Serra da Lousã (LOURENÇO, 1996, p. 248) foram apresentados elementos que nos fazem crer que, entre os séculos XVII e XIX, havia aí frio intenso. Registadas que são, ainda hoje, de vez em quando, no inverno, temperaturas de 10 graus centígrados abaixo de zero, em plena secção terminal do vale do Côa, com que frequência se atingiriam essas temperaturas e a que temperatura se desceria nessas épocas mais frias, mesmo em tempos históricos? Admitimos, porém, que atendendo às características topográficas, estes frios, ao contrário do que poderá ter acontecido em altitude, não teriam tido, localmente, qualquer significado morfogenético.

A agressividade do clima na área em causa, não sendo actualmente muito grande, nem tendo sido demasiada nas últimas centenas ou até nos últimos milhares de anos, em função das características de continentalidade, altitude e topografia, parecia-nos, no entanto, suficiente para criar destruições notáveis em rochas xistosas, aceites como pouco resistentes, tanto pelos seus numerosos pontos frágeis, como microdobramentos e fracturação abundantes, facilmente explorados pelas águas de escorrência, como pela grande susceptibilidade à hidratação das argilas que as constituem. Na sua maior parte, as rochas demonstraram fortes índices de porosidade e elevada fissuração (CORDEIRO e REBELO, 1996, p. 25).

E que dizer do próprio Rio Côa? Será ele um pequeno rio sem importância erosiva?

Quando pensamos em Foz Côa, lembramo-nos do Alto Douro e do calor e da secura da Terra Quente (GIRÃO, 1933, pp. 64 e 90), bem como, por isso mesmo, do vinho generoso da Quinta de Santa Maria da Ervamoira, das oliveiras e das amendoeiras. Mas não devemos esquecer que o Rio Côa corre ali, no fim dos seus $140 \mathrm{~km}$ de extensão, concentrando as águas de uma bacia com cerca de $2430 \mathrm{Km}^{2}$, que nasce na Serra das Mesas, à volta dos $1100 \mathrm{~m}$ de altitude e que logo começa a drenar toda a fachada Norte da Serra da Malcata, para depois drenar a área do Sabugal, parte da Cordilheira Central e a Serra da Marofa, passando já bastante encaixado na Meseta, na área de Vilar Formoso e, mais ainda, na de Cidadelhe ao entrar na área que estudámos (CORDEIRO e REBELO, 1996, p. 12-15).

De verão quase sem água, como pudemos, desde início, observar (começámos o trabalho de campo para a elaboração do estudo geomorfológico do vale em pleno mês de Julho de 1995), mas de inverno com fortes caudais, como já sabíamos, o Côa tem, por vezes, cheias importantes e destruidoras. Mesmo antes de acompanharmos as cheias do início de 1996, já tínhamos conhecimento de outras bem mais violentas, como as de 1989 , quando as suas águas passaram por cima da ponte de Cidadelhe dobrando (ou pura e simplesmente arrancando) parte dos corrimões de ferro. Nas suas cheias, ao longo especialmente dos períodos menos frios das últimas centenas de anos, quantas vezes o Côa não teria passado perto ou mesmo por cima de algumas das gravuras, tal como aconteceu nas cheias do início de 1996, na Penhascosa, onde, segundo informações recolhidas no local, até as danificaram, embora pouco, felizmente.

Por tudo isto, as condições de manutenção das gravuras, mesmo em tempos recentes, não eram as mais favoráveis para se aceitar a datação apresentada pelos arqueólogos. Feitas em xistos, frágeis, como, para grande parte das amostras reco- 
lhidas, se confirmou em laboratório (CORDEIRO e REBELO, 1996, p. 25), encontrando-se algumas tão perto do leito actual que ficam sujeitas à acção das águas fluviais «em fúria» durante as cheias, estão todas submetidas a um clima que, apesar de ser hoje mediterrâneo, de tipo continental, muito seco, ainda tem uma certa agressividade particularmente em situações de chuvas intensas.

2. As primeiras observações de campo que efectuámos no vale do Côa ${ }^{3}$, aparentemente, confirmaram a ideia de que as gravuras não deveriam ser muito antigas.

Apesar de integrado na Terra Quente do Alto Douro, o troço terminal do Rio Côa apresenta vários tipos de depósitos relacionados com o frio da última glaciação (CORDEIRO e REBELO, 1997).

Por exemplo, trabalhados pela erosão fluvial, deslocados já dos sítios onde haviam terminado a sua movimentação em grandes massas lamacentas, os blocos de litologia e dimensões variadas da Penhascosa salientaram-se, desde logo, como testemunho desse período. O modelo já era conhecido doutras áreas do centro-norte de Portugal (ReBelo, 1986, p. 137; PedrosA, 1993, p. 209-214), muito particularmente da Serra da Freita e da rede hidrográfica do Rio Paiva (CORDEIRO, 1986, p. 164-167, 1988, p. 116-117, e 1995, p. 46-47) - clima muito frio, repetição do processo de formação de gelo-degelo e destacamento de blocos nas vertentes, blocos estes que, imediatamente, eram envolvidos em gelifluxões ou que, posteriormente, com o aquecimento do clima, por fusão brusca do gelo ou da neve, ou na sequência de chuvas abundantes, se misturavam com calhaus, areias e argilas deslocando-se, de modo mais ou menos catastrófico, em massa, pelas próprias vertentes ou por valeiros afluentes (onde às vezes ainda se encontram conservados) podendo atingir o vale principal; aqui se viria a processar o seu desmantelamento por acção fluvial até se atingirem as características actuais.

Como facilmente se deduz, esta sequência de processos inicia-se no último momento verdadeiramente frio do Würm, que também se terá feito sentir na região - o pico de frio do Tardiglaciar (Würm final), designado Dryas recente (Dryas 3) - há sensivelmente 10000-10800 anos, datação aceite para o sudoeste de França (LAVILLE et al., 1983, citado por CHALINE, 1985, p. 206), tal como para Portugal e Espanha (CORDEIRO, 1990a e 1995), e muito semelhante à referida para os «episódios climáticos» de Blytt-Sernander (LOWE e WALKER, 1990, p. 133). Pensávamos, então, que só a partir daí passariam a existir as superfícies lisas onde depois se fariam as gravuras. Algumas dessas superfícies, todavia, não se conseguiam relacionar com os vestígios daqueles depósitos; vendo, porém, a diversidade de estados de conservação desses depósitos, não era de admirar que, para jusante da Penhascosa, com o rio mais encaixado, o desmantelamento tivesse

3 Este trabalho de campo inseriu-se num Projecto de Investigação intitulado $O$ vale do Côa e dos seus afluentes a jusante de Cidadelhe, patrocinado pela Hidrorumo, empresa do Grupo EDP, e decorreu no âmbito das actividades do Centro de Estudos Geográficos da Universidade de Coimbra envolvendo, além dos signatários, uma equipa constituida por três recém licenciados em Geografia José Duarte, Rui Figueiredo e Rui Rocha e um então estudante, hoje também licenciado em Geografia, Orlando Marinho. 
sido maior e o transporte em ponta de cheia os tivesse levado progressivamente até ao Douro.

Este modelo, a que se poderá chamar «origem tardiglaciar das superfícies lisas onde se encontram as gravuras», não chocava com o raciocínio teórico que havíamos feito e ia, efectivamente, a favor das datações propostas pelos diversos estudiosos estrangeiros que negavam a hipótese de idade paleolítica, atribuindo às mais antigas gravuras de Foz Côa idades variadas entre o Neolítico e tempos históricos recentes (ZILHÃO, 1995; SOARES, 1995).

3. No entanto, desde o primeiro dia em que pensámos no problema da datação das gravuras de Foz Côa, antes ainda de nos ser proposto o estudo geomorfológico do vale, pusemos hipóteses alternativas àquela que nos parecia mais simples e mais lógica.

Poderia acontecer que os xistos com gravuras conservadas fossem mais resistentes do que a maioria dos xistos que por ali afloram. Ou (porque não?) poderia ter acontecido que, independentemente da sua dureza, os xistos com gravuras tivessem chegado quase incólumes aos nossos dias em virtude de uma eventual cobertura, impermeabilizante, por depósitos de vertente.

$\mathrm{Na}$ verdade, há muitas variedades de xistos e quanto a condições de frio muito semelhantes às do Tardiglaciar sabe-se que ocorreram, até durante mais tempo e por várias vezes, ao longo do chamado Pleniglaciar wurmiano. Houve, portanto, possibilidades de, anteriormente, se formarem superfícies lisas por destacamento de materiais em função da formação de gelo. DAVEAU já há muito alertara para a existência de dois momentos importantes de gelifracção no nosso país (DAVEAU, 1973, p. 20); também CunHA (1990, p. 292), ao estudar a área das Serras de Condeixa, Sicó e Alvaiázere, identificou depósitos com gelifractos correspondendo, apenas, a dois momentos; cremos que, talvez menos importantes, outros momentos terão igualmente ocorrido (REBELO, 1975, p. 119, e 1986, p. 137).

Por tudo isto, o trabalho de campo, iniciado nas acumulações sedimentares de Penhascosa, dirigiu-se, desde princípio, também, para a observação das superfícies lisas de xisto em que se encontram gravuras consideradas antigas, e do conjunto da área das vertentes onde elas se integram.

No que respeita às superfícies lisas, rapidamente se concluiu que as gravuras, embora feitas em xistos de características diversas, não o foram sobre planos de xistosidade ou sobre planos de estratificação, mas sim em planos de fracturação, às vezes, claramente enriquecidos por óxidos, o que só por si parecia não ser suficiente, mas já ajudava a compreender uma maior resistência aos diversos processos de erosão que se sucederam ou conjugaram desde o tempo das gravações até hoje. Além disso, esses planos de fracturação com gravuras encontram-se quase sempre muito perto da vertical, uma ou outra vez até em contra-declive, dificultando, portanto, a acção das águas de escorrência que, ou passam por eles muito rapidamente, ou não chegam mesmo a passar. O efeito das chuvas intensas sobre as gravuras acaba, assim, por ser mínimo - na maior parte dos casos, a acção mecânica ficará dependente da força do vento para atirar as gotas de água contra a superfície rochosa e a acção físico-química da água parece ser reduzida uma vez 
que ela não permanece encharcando a rocha, apenas a deixa molhada por pouco tempo.

Claro que as características de dureza, mais concretamente de porosidade e de capacidade de absorção de água, e de colocação vertical ou subvertical desses planos não impediriam o ataque erosivo pelo frio. Com muito frio, mesmo que com pouca água disponível, dadas as características físicas das rochas, a formação de gelo seria inevitável e levaria à fragmentação da rocha. Salvo casos muito especiais de conjugação de verticalidade com especial resistência da superfície rochosa, as gravuras, se já lá estivessem, muito provavelmente desapareceriam.

Não se nos afigurava, deste modo, possível a hipótese da manutenção perfeita das superfícies lisas, logo, das gravuras, sob a acção directa dos processos relacionados com o frio muito intenso - difícil, portanto, aceitar que tivessem subsistido incólumes ao pico de frio tardiglaciar e, particularmente, ao longo período frio do Pleniglaciar superior... a menos que, estando feitas as gravuras há muito tempo, essas superfícies tivessem sido cobertas por depósitos que as imunizassem de ataques erosivos por esse frio muito intenso.

4. Era, então, fundamental procurar, junto das gravuras, vestígios de depósitos susceptíveis de terem exercido essa função protectora.

Na Penhascosa, vêem-se, facilmente, depósitos finos a cobrir parte de uma superfície rochosa com gravuras; mas também facilmente se deduz (e comprova-se em laboratório) que esses depósitos são fluviais e se relacionam com as cheias do Côa. No entanto, uma dúvida muito forte surge nesse mesmo local - quando os homens fizeram aquelas gravuras decerto que o rio não inundava a área com a frequência com que hoje o faz. Não estaria o rio, ali, bem mais abaixo do que está hoje? A que se deveu, então, o entulhamento? Teria sido ao já referido depósito heterométrico vindo de afluentes próximos em condições eventualmente catastróficas, ou seja, bruscamente? Se foi, e tudo indica que em grande parte o foi, essas gravuras foram feitas, noutras condições topográficas, antes do pico de frio do Tardiglaciar e tiveram forçosamente de estar cobertas, como que fossilizadas, por depósitos que impediram o ataque do frio e até a destruição mecânica que o depósito heterométrico, primeiro, e as cheias consecutivas do Côa, depois, teriam, sem dúvida, originado.

Nesse local preciso, infelizmente, eles não se encontraram. Porém, o trabalho de campo, alargado a toda a área do Côa e dos seus afluentes a jusante de Cidadelhe, veio demonstrar a existência de depósitos igualmente relacionados com o frio um pouco por todo o lado. Encontraram-se depósitos de características muito variadas, desde aqueles depósitos heterométricos, de duas gerações diferentes, até depósitos homométricos, de patelas de xisto, inequivocamente de origem periglaciar, bem demonstrada, aliás, pela existência de «edifícios periglaciares» típicos, com crioclasto, touca e «squeletane» (CORDEIRO e REBELO, 1997), relacionados com movimentações lentas em tempos de frio húmido intenso, susceptíveis de terem regularizado grande parte das vertentes (CORDEIRO e REBELO, 1996, p. 21-27).

Enquanto os primeiros ocupavam fundos de vale, estes últimos, cobrindo formas anteriores das vertentes, poderiam ter sido os responsáveis pela fossilização 
de superfícies rochosas com gravuras. Todavia, junto às gravuras, só os encontrámos uma vez. Trata-se da chamada rocha 3 da Canada do Inferno, onde ainda cobriam uma parte da superfície rochosa lisa na qual se podem observar gravuras consideradas paleolíticas (BAPTISTA e GOMES, 1995).

Não é fácil descobrir muitos casos semelhantes. Seria necessário fazer mais escavações e ter sorte... Na realidade, após o último pico de frio do Tardiglaciar, durante o Holocénico, houve diversos períodos pluviosos, mas principalmente uma grande interferência do Homem sobre as vertentes, muitas vezes através do desencadeamento de incêndios (DAVEAU, 1980 e 1988; CORDEIRO, 1990 b; RENAULT-MisKOVSKY, 1991), que, se não afectaram demasiado as paredes rochosas onde estão as gravuras, actuaram naturalmente sobre os planos mais ou menos inclinados das vertentes, ou seja, actuaram sobre os taludes regularizados com os depósitos de que agora apenas encontramos vestígios.

Para compreender isto, basta ver como ainda hoje, nas vertentes da secção terminal do Côa, quando se verificam chuvas intensas, as águas de escorrência rapidamente se tornam lamacentas e transportam areias e pequenos calhaus. Estes factos de observação podem ser comparados com os que levaram aos elevados valores de erosão calculados por PEDROSA (1993, p. 374) e por LOURENÇO (1996, p. 470), em situações semelhantes de pouca a nenhuma cobertura vegetal, no interior de áreas amostra estabelecidas, respectivamente, na Serra do Marão e na Cordilheira Central.

Foi assim durante milénios. Por isso, não se duvida de que só este processo erosivo poderia ter posto progressivamente a descoberto superfícies rochosas com gravuras antigas.

Algumas das gravuras poderão, todavia, nunca ter estado fossilizadas. A maior dureza (e a menor porosidade) e a verticalidade da superfície rochosa gravada, associadas a uma posição de cornija, alta, na vertente, poderão ter sido motivos suficientes para explicar uma não regularização por depósitos periglaciares e uma manutenção até agora, apesar do último pico de frio do Tardiglaciar e das acções erosivas posteriores.

Há, efectivamente, casos em que isso parece ter acontecido. Saliente-se, a título de exemplo, a chamada rocha 15 da Canada do Inferno, onde as marcas da actuação do gelo são tão fortes que não deixam dúvidas quanto à sua exposição durante um pico de frio muito intenso que, na área, não será fácil aceitar como localizado em tempos históricos. No mínimo, resultarão do referido pico de frio do Tardiglaciar, mas poderão ter resultado dos últimos tempos frios e húmidos do Pleniglaciar superior.

Em conclusão, quando a rocha com gravuras se encontra razoavelmente conservada, estaremos certamente na presença de algo que veio a ser posto a nu, após um período de cobertura com depósitos a partir dos quais, à superfície, se desenvolveram argilas capazes de fornecer uma forte impermeabilização; quando a superfície rochosa com gravuras está muito marcada pelo frio, é provável que não tenha havido cobertura ou, se a houve, que tenha sido de curta duração. 
5. Os estudos geomorfológicos já realizados e os que ainda estão em curso, embora sem atingirem, no respeitante à morfocronologia, um elevado grau de precisão, vêm dar força às datações apresentadas pelos arqueólogos portugueses, no sentido de que há gravuras paleolíticas.

Não temos dúvidas, efectivamente, de que há, em Foz Côa, no conjunto dos «milhares de gravuras, que podem ser datadas desde o Paleolítico superior até à Idade do Ferro e mais tarde» (V. JORGE e S. JORGE, 1995, p. 19-20), gravuras feitas há mais de 10000-10800 anos. Muito antes ou pouco antes é mais difícil de saber.

Se pensarmos em condições favoráveis à vida humana existentes antes desse pico de frio e estabelecermos a comparação com o que se conhece para a Serra do Caramulo (CORDEIRO, 1990 b, p. 55), algumas delas poderiam ter sido feitas durante o aquecimento do Tardiglaciar que se iniciou pelos 15500 anos BP, um pouco mais cedo, portanto, que noutros pontos da Europa, como se compreenderá tendo em conta os factores geográficos em jogo (REBELO, 1995); este período favorável poderia vir até há 13000 anos, talvez mesmo até há 11000 .

No entanto, se pensarmos que os depósitos estratificados de vertente, quase homométricos, periglaciares, oriundos dos xistos, e os que lhes são aparentados provenientes dos granitos, que também foram identificados perto, precisaram de algum tempo para se formarem e de muito tempo para evoluirem pelas vertentes até atingirem as características que hoje apresentam, somos levados a concluir que a última vez que se poderiam ter começado a formar seria bem antes dos $15500 \mathrm{BP}$, durante os tempos frios imediatamente anteriores. No sudoeste de França, eles teriam começado há uns 18800-19000 (CHALINE, 1985, p. 206); se estivéssemos em França, as gravuras que têm sido consideradas paleolíticas poderiam ser do interestádio anterior, ou seja do período de aquecimento situado entre o Pleniglaciar superior e o Tardiglaciar (Würm III e Würm IV - Laugerie - 20000-19000 BP, segundo CHALINE, 1985, p. 206, ou 18000-17000 BC, consoante RENAULT-MISKOVSKY, 1991, p. 146). O mesmo raciocínio, mas agora introduzindo os factores geográficos já referidos, poderá levar-nos um pouco mais longe para o caso de Foz Côa - com todas as dúvidas inerentes à fiabilidade de uma só datação pelo C14 para um paleossolo na Serra do Marão (PEDROSA, 1993, p. 199), o valor encontrado (21340 \pm 350$)$ poderia significar um começo precoce deste interestádio no nosso país.

O mais certo, porém, é que, por essa altura, as condições de frio húmido do Pleniglaciar superior fossem favoráveis à formação de depósitos periglaciares capazes de cobrir as vertentes onde poderiam eventualmente encontrar-se superfícies rochosas lisas muito resistentes.

Recuar tanto no tempo é extremamente difícil, mas se aceitarmos como válidas as datações da base e do topo de um paleossolo da mesma Serra do Marão (PEDROSA, 1993, p. 199), entre, aproximadamente, os 28000 e os 24000 BP, ou as datações próximas de 28000-29000 em Varzielas, Serra do Caramulo (CORDEIRO, 1995, p. 42), teríamos aí um interestádio em que algumas rochas estariam em condições de receber as mais antigas gravuras de Foz Côa. Períodos de frio intenso no Pleniglaciar superior são, todavia, bem conhecidos e, antes destes períodos menos frios, as condições para a formação de depósitos de vertente de 
características periglaciares estiveram sem dúvida presentes, muitas vezes regularizando as vertentes de tal maneira que não deixaram marcas de cornijas - ou não tivéssemos, a cerca de $80 \mathrm{~km}$ de distância de Foz Côa, inequívocos testemunhos do grande glaciar wurmiano de planalto da Serra da Estrela (DAVEAU, 1971).

Uma conclusão importante parece ainda poder tirar-se destes estudos. Os métodos mais modernos de datação absoluta que foram utilizados no caso das gravuras estilisticamente consideradas paleolíticas deram valores muito variados, mas sempre inferiores aos que propomos. Apesar de terem sido criticados (ZILHÃO, 1995; SOARES, 1995), admitimos que, independentemente de certas deficiências metodológicas, alguns desses valores possam estar correctos embora não correspondam à idade real das gravuras. Em vários casos, deverão corresponder ao seu tempo de exposição aos agentes erosivos. Como vimos, esse tempo não foi igual para todas - se a cobertura pelos depósitos de vertente poderá, para muitas das gravuras, ter ocorrido quase em simultâneo, a sua exumação foi acontecendo ao longo de milhares de anos, mais cedo para umas, mais tarde para outras, algumas podendo ainda estar como que fossilizadas à espera de novas acções da escorrência ou de uma simples escavação levada a cabo pelos arqueólogos.

\section{BIBLIOGRAFIA}

BAPTISTA, A.; M. GoMES, (1995) - Arte rupestre do vale do Côa. 1. Canada do Inferno. Primeiras impressões. Dossier Côa, SPAE, Porto: 46-118.

Chaline, J. (1985) - Histoire de l'Homme et des Climats au Quaternaire. Doin, Paris.

CORDEIRO, A. (1986) - Nota preliminar sobre formas e formações periglaciares na Serra da Freita. Cadernos de Geografia, 5, Coimbra: 161-172.

CORDEIRO, A. (1988) - A evolução das vertentes da Serra da Freita no Quaternário recente. Cadernos de Geografia, 7, Coimbra: 87-133 + 1 esboço geomorfológico.

Cordeiro, A. (1990 a) - O depósito de Varzielas (Serra do Caramulo). Contribuição para o estudo do Tardiglaciar wurmiano em Portugal. Cadernos de Geografia, 9, Coimbra: 49-60.

CORDEIRO, A. (1990 b) - Paleo-ambientes holocénicos e erosão: interface clima, vegetação, homem. O exemplo do centro-litoral português. Cadernos de Geografia, 9, Coimbra: 61-79.

CORDEIRO, A. (1995) - A provável evolução paleoclimática do Pleistocénico final no Centro-litoral de Portugal (Montanhas Ocidentais). Actas da $3^{a}$ Reunião do Quaternário Ibérico, Coimbra: 39-48.

CoRdeIRO, A.; F. REBelo (1996) - Carta geomorfológica do vale do Côa a jusante de Cidadelhe. Cadernos de Geografia, 15, Coimbra: 11-33.

Cordeiro, A.; F. REbelo (1997) - Os depósitos do vale do Côa a jusante de Cidadelhe (no prelo).

CunHA, L.(1990) - As Serras Calcárias de Condeixa-Sicó-Alvaiázere. Instituto Nacional de Investigação Científica, Coimbra. 
Daveau, S. (1971) - La glaciation de la Serra da Estrela. Finisterra, Revista Portuguesa de Geografia, 6 (11), Lisboa: 5-40.

DAVEAU, S. (1973) - Quelques exemples d'évolution quaternaire des versants au Portugal. Finisterra, Revista Portuguesa de Geografia, 8 (15), Lisboa: 5-47.

Daveau, S. (1980) - Espaço e tempo. Evolução do ambiente geográfico de Portugal ao longo dos tempos pré-históricos. Clio, Revista do Centro de História da Universidade de Lisboa, 2, Lisboa: 13-37.

DAVEAU, S. (1988) - Progressos recentes no conhecimento da evolução holocénica da cobertura vegetal em Portugal e nas regiões vizinhas. Finisterra, Revista Portuguesa de Geografia, 23 (45), Lisboa: 101-115.

Daveau, S. e colaboradores (1977) - Répartition et Rythme des Précipitations au Portugal. CEG, Memórias, 3, Lisboa.

Daveau, S. e colaboradores. (1980) - Dois Mapas Climáticos de Portugal. Nevoeiro e nebulosidade. Contrastes térmicos. CEG, Linha de Acção de Geografia Física, Relatório, 8, Lisboa, 50 p. pol. + 2 mapas a preto e branco; idem (1985), Memórias do Centro de Estudos Geográficos, 7, Lisboa.

GIRÃo, A. (1933) - Esboço duma Carta Regional de Portugal. Imprensa da Universidade, Coimbra.

JoRge, V.; S. JoRge (1995) - Portuguese rock art: a general view. Dossier Côa, SPAE, Porto: 19-43.

Lourenço, L. (1996) - Serras de Xisto do Centro de Portugal. Contribuição para o seu conhecimento geomorfológico e geo-ecológico. Dissertação de Doutoramento, Faculdade de Letras, Coimbra, $757 \mathrm{p}$.

LOWE, J.; M. WALKER (1990) - Reconstructing Quaternary Environments. Longman Scientific and Technical, Harlow.

Pedrosa, A. (1993) - Serra do Marão. Estudo de Geomorfologia. Dissertação de Doutoramento, Faculdade de Letras, Porto.

Pedrosa, A. (1994) - As actividades humanas e os processos morfogenéticos. O exemplo da Serra do Marão. Territorium, 1, Coimbra: 23-34.

ReBElo, F. (1975) - Serras de Valongo. Estudo de Geomorfologia. Suplementos de Biblos, 9, Coimbra.

Rebelo, F. (1986) - Modelado periglaciar de baixa altitude em Portugal. Cadernos de Geografia, 5, Coimbra: 127-137.

REBELO, F. (1995) - Factores geográficos na explicação da génese e cronologia dos depósitos continentais quaternários. Actas da $3^{a}$ Reunião do Quaternário Ibérico, Coimbra: 127-133.

Renault-Miskovsky, J. (1991) - L' Environnement au Temps de la Préhistoire. Masson, Paris.

Ribeiro, O.; LaUtensach, H.; DaVeau, S. (1987) - Geografia de Portugal. II. O Ritmo Climático e a Paisagem. Sá da Costa, Lisboa: 337-623.

SOARES, A. (1995) - Os métodos de 'datação directa' aplicados ao Côa. Dossier Côa, SPAE, Porto: 195-203. 
ZILHÃO, J.(1995) - The stylistically paleolithic petroglyphs of the Côa valley (Portugal) are of paleolithic age. A refutation of their 'direct dating' to recent times. Dossier Côa, SPAE, Porto: 119-166. 